\title{
O USO DO CASO TALIDOMIDA AUXILIANDO NA CONSTRUÇÃO DE SIGNIFICADOS EM AULAS DE QUÍMICA DO ENSINO SUPERIOR
}

\author{
Leandro Antonio de Oliveira ${ }^{\mathrm{a}}$ e Ana Luiza de Quadros ${ }^{\mathrm{b}, *,(\mathbb{0}}$ \\ ${ }^{a}$ Faculdade de Educação, Universidade Federal de Minas Gerais, 31270-901 Belo Horizonte - MG, Brasil \\ bDepartamento de Química, Instituto de Ciências Exatas, Universidade Federal de Minas Gerais 31270-901, Belo Horizonte - \\ MG, Brasil
}

Recebido em 13/08/2019; aceito em 28/11/2019; publicado na web em 05/03/2020

\begin{abstract}
THE USE OF THE THALIDOMIDE CASE IN THE CONSTRUCTION OF MEANING IN HIGHER EDUCATION CHEMISTRY CLASSES. Studies conducted in the field of education have, in many cases, highlighted the little insertion of teaching and learning theories in Natural Sciences classes, in Higher Education. We developed this study to analyze how Chemistry professors take ownership of a historical case to explain the concepts they develop in their classes. To do so, we analyzed this record of undergraduate classes, at times when professors related pedagogical link-making to the future field of work of the students, using the "Thalidomide case." We realized that, by showing the importance of studies involving chirality and related concepts, the students' attention to the content seems to have increased significantly, which expands the possibilities of construction of meaning. Thus, we argue that the pedagogical link-making can significantly contribute to students' knowledge.
\end{abstract}

Keywords: pedagogical link-making; Higher Education; Chemistry, thalidomide.

\section{INTRODUÇÃO}

Pesquisas no campo da formação de professores do Ensino Superior indicam que os conhecimentos docentes daqueles que lecionam na área das Ciências da Natureza, como é o caso da Química, são construídos em programas de pós-graduação de campos específicos do saber, nos quais não há uma atenção sistemática com a formação pedagógica. ${ }^{1-3}$ Além disso, a organização das instituições públicas tende a privilegiar a pesquisa em detrimento do ensino e da extensão. Assim, o tempo de trabalho desses professores acaba sendo mais dedicado à pesquisa, o que resulta em menor disponibilidade para o desafio da docência.

Trabalhos recentes têm sido publicados envolvendo a docência no Ensino Superior, na área de Ciências da Natureza, dentre os quais citamos, a título de exemplo, pesquisas envolvendo: análise da expressividade dos professores universitários; ${ }^{4}$ estratégias usadas em sala de aula por professores bem avaliados $;^{5-7}$ ensino por projetos de investigação; ${ }^{8}$ estudo dos gestos,${ }^{9,10}$ estudo da multimodalidade, ${ }^{11}$ estudo do contrato didático $;^{12}$ e estudo da avaliação. ${ }^{13}$

Nesses trabalhos é recorrente a insatisfação com o fato de as universidades não fornecerem uma atenção para a formação continuada do professor universitário, por meio de estudos de teorias de ensino e de aprendizagem e que essa formação aconteça ancorada na experiência didática de cada professor. Também são recorrentes comentários relativos à fragmentação do currículo, o que dificulta ao estudante perceber a importância de cada um dos tópicos trabalhados dentro das diferentes disciplinas.

Neste trabalho, fazemos um estudo de caso no qual a talidomida, um medicamento ingerido por gestantes com a intenção de evitar as náuseas e enjoos típicos da primeira fase da gravidez, foi explorado por professores em três diferentes disciplinas da graduação, para relacionar com o conteúdo discutido nas aulas ou para auxiliar na construção de uma visão mais ampla da própria Química. Nosso objetivo central foi de analisar como esses professores se apropriaram

*e-mail: aquadros@qui.ufmg.br de um caso histórico para dar significado aos conceitos que desenvolveram em suas aulas.

\section{APORTE TEÓRICO}

Sabemos que o ensino e a aprendizagem em sala de aula são processos que se organizam em função do fator "tempo", ou seja, professores planejam os conteúdos considerando o tempo de aula que têm disponível, ficando aos estudantes a tarefa de se apropriar adequadamente dos conceitos envolvidos nesse conteúdo. Geralmente, as necessidades pedagógicas não são levadas em conta para que essa apropriação aconteça.

Alguns estudos ${ }^{14-16}$ têm sugerido que a aprendizagem depende, também, das oportunidades oferecidas aos estudantes para que possam significar dado conhecimento, ou seja, para que o conhecimento desenvolvido em sala de aula faça sentido para eles. Isso poderia acontecer, por exemplo, quando o professor organiza uma sequência coerente de tópicos que permita ao estudante desenvolver vínculos entre aquilo que ele já sabe ou já conhece com o novo conhecimento que lhe é apresentado.

Ao se referirem à contextualização, Rivet e Krajcik ${ }^{17}$ afirmam que situações ou eventos particulares que tenham ocorrido em um contexto diferente da sala de aula geralmente são de particular interesse dos estudantes, motivando-os à medida que percebem que as ideias, os conceitos e os conteúdos da Ciência têm relação explícita com o mundo real. Silseth ${ }^{18}$ afirma que o uso de um conhecimento do cotidiano como ferramenta cultural torna-se um recurso cognitivo que orienta a aprendizagem e apoia a compreensão dos estudantes em relação aos temas acadêmicos e aos conceitos científicos. Wiig, Silseth e Erstad ${ }^{19}$ alertam que situações do contexto deveriam surgir dos próprios estudantes, para que eles realmente sejam capazes de conectar seus próprios conhecimentos e experiências aos conceitos científicos. Porém, esses autores afirmam que os professores raramente solicitam aos estudantes esse tipo de relação.

Rocksén e Olander ${ }^{20}$ explicitam que o estabelecimento de relações entre unidades de conteúdo para promover a construção de significados é evidente nas ciências naturais e que as práticas referenciais são 
de particular valor para o avanço de argumentos científicos. Com isso, elas defendem o uso de diversos tipos de relações de conteúdo, que contribuam para a coerência na construção individual de significados, bem como para a construção de entendimentos mútuos.

Ao analisarem a criação de relações pedagógicas ${ }^{16}$ durante o desenvolvimento de uma sequência didática de "Evolução", em uma escola de ensino médio da Suécia, Rocksén e Olander ${ }^{20}$ afirmaram que utilizar experiências passadas contribui para construir aprendizagens. Porém, reconhecem a necessidade de investigações adicionais sobre como professores criam relações pedagógicas em escala macroscópica e entre as diferentes disciplinas escolares.

Havekes et al. ${ }^{21}$ se basearam nos estudos de Scott, Mortimer e Ametller, ${ }^{16}$ e produziram um conjunto de aulas para desenvolver o pensamento científico e histórico, relacionando-os. A sequência proposta por eles ${ }^{21}$ foi desenvolvida por cinco professores de diferentes escolas da Holanda e a análise se deu sobre a performance do professor ao lidar com a linguagem da ciência e a linguagem do cotidiano, usadas pelos estudantes, e os possíveis insights de aprendizagem que pudessem ser observados. Considerando a prática dos professores envolvidos, os pesquisadores afirmam que as ideias epistêmicas dos professores sobre como estudantes aprendem a pensar historicamente influenciam na prática pedagógica e no comportamento do professor. No entanto, segundo eles, o entendimento de como essa influência acontece é um desafio para pesquisas futuras.

Scott, Mortimer e Ametller ${ }^{16}$ propuseram a noção de "Relações Pedagógicas" tanto como uma ferramenta para analisar a aula quanto para orientar a prática docente. Segundo os autores, essa proposta está diretamente relacionada às maneiras pelas quais professores e estudantes fazem conexões entre ideias e conceitos, que são consideradas fundamentais para a construção de significados em sala de aula.

Ao analisarem uma sala de aula do Reino Unido, esses pesquisadores ${ }^{16}$ identificaram três formas principais de criação de relações pedagógicas: para promover a continuidade; para apoiar a construção de conhecimento; e para encorajar o envolvimento emocional. As duas primeiras são subdivididas em vários níveis, conforme pode ser observado na Figura 1.

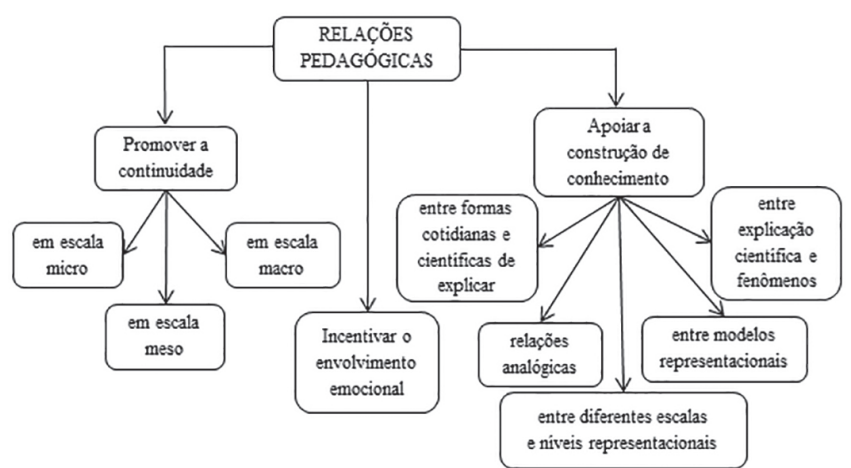

Figura 1. Síntese das Relações Pedagógicas propostas por Scott, Mortimer e Ametller ${ }^{16}$

A proposta envolvendo relações pedagógicas parte de uma ideia construtivista básica, na qual o professor orienta a aprendizagem dos estudantes pela construção individual e coletiva do conhecimento, ao relacionar as ideias que os estudantes possuem com as novas informações trabalhadas em sala de aula. As relações que apoiam a construção do conhecimento, segundo os autores, ${ }^{16}$ envolvem ao menos seis abordagens, conforme Figura 1. As relações de continuidade, por sua vez, envolvem eventos separados no tempo. Para o ensino superior, nos ancoramos em outros autores, ${ }^{22}$ dividindo essas relações da seguinte maneira: micro, quando a relação entre conceitos/ conteúdo ocorre em uma mesma aula; meso, quando ocorre dentro da mesma disciplina; macro, quando ocorre com outras disciplinas ou até mesmo com outro nível da educação.

Com isso, se organiza o que os autores ${ }^{16}$ chamam de estória científica. O principal argumento desses autores é que o desenvolvimento de uma estória científica estabelece continuidade ao longo de um período de tempo e que é um elemento-chave para uma educação científica de qualidade.

Entre as relações que apoiam a construção do conhecimento destacamos as relações entre explicações científicas e as cotidianas e as relações entre o conhecimento científico e os fenômenos. Nas salas de aula do Ensino Superior temos percebido que essas relações nem sempre acontecem, principalmente quando se trata de conhecimento químico. No entanto, sendo essa uma tendência contemporânea de ensino, o contexto tem sido levado em conta em muitos trabalhos, que tratam do ensino de Química, presentes na literatura.

Neste trabalho exploramos a tentativa que três professores de Ensino Superior fazem para tornar o conteúdo químico que ensinam em suas aulas mais significativo para os estudantes. Para isso, eles se apropriaram de um acontecimento da década de 1950 - o caso "talidomida" - ao ensinar Química Orgânica e Química Inorgânica. Com isso, foi explorado um fato histórico que, apesar de graves consequências para a sociedade, fez com que a Ciência dedicasse mais atenção à quiralidade de substâncias químicas, principalmente na produção de fármacos, e a sua importância na interação com organismos vivos.

O caso talidomida já foi explorado para ensinar Química em outros contextos e com outros enfoques. Por isso, selecionamos alguns trabalhos que exploraram a talidomida como estudo de caso para ensinar Química.

\section{Pesquisas envolvendo o uso da talidomida em aulas de Química}

A droga talidomida foi lançada no mercado, na década de 1950, por uma pequena empresa alemã, para controlar sintomas como ansiedade, tensão e náuseas. Isso fez com que esse medicamento ficasse bastante popular entre gestantes, em vista da sua eficácia no combate aos recorrentes sintomas da gravidez. Segundo Hoffman, ${ }^{23}$ em 1957 o produto já era comercializado em 147 países. Entre 1959 e 1960 vários casos de má formação congênita levaram ao estudo dessa droga, descobrindo seus efeitos teratogênicos. As pesquisas destacaram a importância dos isômeros ópticos, formados a partir da presença de um carbono quiral (Figura 2), ou seja, um carbono com quatro grupos ligantes diferentes.

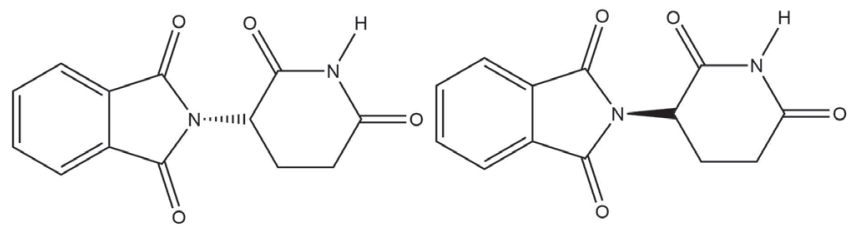

Figura 2. Representação dos isômeros ópticos presentes na talidomida

Estima-se que cerca de oito mil crianças tenham nascido com deformidades congênitas graves em função do consumo de talidomida pelas mães, durante a gravidez. No Brasil essa história é ainda mais perversa, pois além da droga ter sido retirada do mercado com certo "atraso", e seu uso no tratamento de outras doenças (Lúpus, Câncer, Leucemia, Vitiligo, Aftas, Tuberculose etc.) associado à desinformação, originaram duas outras gerações de crianças vitimadas pela droga. Trata-se, portanto, de um fato histórico marcante, em nível mundial, tanto pelo seu impacto quanto pela noção que ele nos traz sobre a importância de estudos químicos especializados na área de medicamentos. 
Com isso, o caso "talidomida" tem sido explorado no ensino de Química, tanto na Educação Básica quanto no Ensino Superior. Buscamos na literatura alguns exemplos de uso desse caso, tido como fato histórico, os quais descrevemos brevemente a seguir.

Na Educação Básica, ao desenvolver conteúdo de isomeria no Ensino Médio, Souza ${ }^{24}$ propôs aos estudantes que apresentassem trabalhos de temas correlatos. Um dos grupos escolheu o tema "Medicamentos e talidomida". Ao final do trabalho os estudantes participantes foram entrevistados e, segundo a autora, durante essas entrevistas se mostraram muito "tocados" pelo caso talidomida e pareceram ter percebido a importância do estudo de isomeria. Aquino e Cavalcanti ${ }^{25}$ relatam uma experiência na qual os estudantes foram envolvidos na produção de vídeos de curta duração, com temas relacionados à Química Orgânica. Um dos curtas constrói uma estória fictícia de uma jovem que engravida e é indicado a ela tomar talidomida. Considerando que a jovem desconhecia os possíveis efeitos colaterais da droga, o grupo propôs o estudo da substância, com ênfase na isomeria óptica. Sulzbach ${ }^{26}$ desenvolveu uma sequência de experimentos envolvendo isomeria e um deles específico da isomeria óptica. Ao que parece, a talidomida e sua história estavam contempladas no material didático dos estudantes. Porém, na discussão dos resultados, esse tema não se mostrou significativo, já que praticamente não apareceu. Já Gomes e Costa $^{27}$ analisaram os dados de dois minicursos ofertados em uma universidade, para estudantes em geral. A participação se deu quase que exclusivamente com estudantes da Educação Básica. Segundo os autores, entre os diversos temas trabalhados envolvendo fármacos, a talidomida foi o que mais impactou os participantes, que se referiram a ela em diversos momentos da coleta de dados.

No Ensino Superior, há duas investigações envolvendo livros didáticos e duas em sala de aula. Raupp e Del Pino ${ }^{28}$ analisaram informações históricas e contextuais presentes em quatro livros didáticos de Química usados no Ensino Superior, com ênfase para o conteúdo de estequiometria. Eles afirmam que a estereoquímica é um tema com potencial para ser relacionado às aplicações cotidianas e à sua evolução histórica. Além disso, os autores afirmam que um dos tópicos normalmente presentes nos livros didáticos é o "famoso e trágico" caso da talidomida. Silva, Costa e Marcelino Jr., ${ }^{29}$ por sua vez, examinaram o conteúdo envolvendo fatores históricos da isomeria, presente em quatro livros didáticos de Química Orgânica. Segundo os autores, três desses livros abordam o caso da talidomida. Porém, em função dos critérios utilizados por eles, o livro que não tem esse caso foi considerado como o mais indicado.

Almeida, Mendes e Dalpizzol, ${ }^{30}$ descrevem uma experiência em que foi discutido o oficio de farmacêutico em um curso de Farmácia. Os autores usam alguns acontecimentos trágicos no contexto dessa profissão e, entre eles, o exemplo da talidomida. O foco desse trabalho foi a valorização da profissão, sem uma relação clara com o ensino de Química. Magedanz, Herber e Silva ${ }^{31}$ fazem uma discussão acerca de abordagens ativas para o Ensino Superior, nas disciplinas de Introdução às Ciências Exatas, Química Orgânica I e Tratamento de Efluentes, durante um programa de formação continuada de professores universitários. Dentre as experiências vividas durante o programa, um grupo de estudantes investigou o caso da talidomida. Os estudantes afirmaram que o envolvimento com o tema facilitou o entendimento do conteúdo de isomeria, trabalhado nas aulas seguintes.

\section{METODOLOGIA}

Esta investigação surgiu a partir de uma pesquisa mais ampla na qual um dos autores buscou investigar o uso de meios mediacionais por professores de Química do Ensino Superior em uma universidade federal..$^{32}$ Nessa pesquisa, foram filmadas sequências de aulas de professores universitários, dois de cada área básica da Química (Química Geral, Físico-química, Analítica, Orgânica e Inorgânica) que ministravam aulas para graduandos de diferentes cursos de Ciências da Vida e da Natureza.

Ao retomarmos o conjunto de aulas filmadas, chamou-nos a atenção o fato de que três professores - Aline, Rosa e Mateus (nomes fictícios) - tratavam do tema geral Isomeria de substâncias. Os três professores pertencem ao corpo docente do Departamento de Química da Universidade.

Aline tem 22 anos de experiência docente e leciona disciplinas na área de Química Orgânica. No contexto desta pesquisa ela ministrava Química Orgânica I em 2016. Estavam matriculados na disciplina de Aline estudantes dos cursos de Química Bacharelado, Química Licenciatura e Química Tecnológica. Rosa, a outra professora de Química Orgânica investigada, possui 17 anos de experiência docente, ministrava a disciplina de Química Orgânica I para estudantes do curso de Farmácia. A ementa de Química Orgânica I, disciplina geralmente ofertada nos primeiros períodos de vários cursos da área de Ciências da Natureza, orientava professores a tratar dos subtemas (i) compostos de carbono representativos e grupos funcionais; (ii) interações intermoleculares; (iii) introdução às reações orgânicas: ácidos e bases; (iv) estereoquímica; e (v) propriedades, sínteses e reações de hidrocarbonetos.

Mateus, por sua vez, é um professor da área de Química Inorgânica, com 37 anos de experiência docente. Ele ministrava, nesse contexto de pesquisa, aulas de Química Inorgânica I para estudantes do curso de Farmácia. A ementa da disciplina orientava os professores a abordar: (i) Teoria dos Orbitais Moleculares; (ii) introdução ao estudo de complexos; (iii) ligações químicas nos complexos; (iv) conceitos de ácidos e bases; e (iv) estudo de materiais inorgânicos. O tema Introdução ao estudo de complexos contempla o estudo de Isomeria dos complexos inorgânicos.

Esses três professores usaram o caso da talidomida como exemplo de medicamento que apresentava uma mistura de dois enantiômeros com propriedades diferentes, explorando os efeitos colaterais causados em embriões humanos quando a talidomida era usada por gestantes.

A partir dos vídeos dessas aulas - que eram parte do banco de dados do grupo de pesquisa - construímos mapas de episódios. Segundo Mortimer e colaboradores, ${ }^{33}$ episódios são constituídos por um conjunto coerente de ações, realizadas por algum(uns) participante(s), que apresentam início e fim claros, podendo os episódios serem diferenciados daqueles que os precedem e os sucedem. Como exemplo de mudança de episódio citamos duas ações realizadas pelo professor durante a aula: a mudança da temática e a apresentação de um exemplo específico para suceder a explicação de um conceito geral. Cada um dos conjuntos de ações nesses dois agrupamentos, utilizados como exemplo, certamente apresentariam uma composição de elementos que as caracterizariam como situações distintas: intencionalidade do professor, composição linguística e diferentes significados, além de apresentarem início, meio e fim bem claros. Se após essa exemplificação, o professor resolvesse um exercício no quadro que se referisse a uma situação ou contexto diferentes do exemplo apresentado no episódio anterior, o conjunto de ações, nesse momento, provavelmente se apresentaria como um novo episódio, consideradas as particularidade das ações e das intenções do professor. Normalmente há, nas transições entre episódios, pistas linguísticas que demarcam seus limites. Por exemplo, o uso de expressões gestuais, de algumas expressões no discurso verbal (ok? Tudo certo? Tudo bem? Entenderam? Alguma dúvida?), pausas longas entre orações do discurso ou até mesmo variação (elevação ou diminuição) nas entonações da fala de um termo para outro, geralmente sinalizam as delimitações entre os episódios. 
Na macroanálise fragmentamos cada uma das três aulas em episódios, considerando, para isso, como os professores abordaram os conceitos, leis, situações e teorias, bem como as pistas linguísticas que foram evidenciadas nas transições entre eles, originando os mapas de episódios. Esses mapas possibilitaram visualizar a totalidade dos dados e dos objetivos e das ações dos professores durante suas aulas. Isso também nos auxiliou a compreender o momento da introdução do exemplo da talidomida, objeto de nosso interesse, nas ações de cada um deles.

Com o mapa de episódios de cada aula, identificamos os episódios em que Aline, Rosa e Mateus exploraram o caso da talidomida e os transcrevemos, para facilitar a microanálise. Na etapa de microanálise analisamos como o caso foi explorado por cada um dos professores, as relações que fizeram do caso com os conceitos científicos e quais as possíveis contribuições para que os estudantes significassem os conceitos trabalhados.

\section{RESULTADOS}

Os fragmentos selecionados apresentam o uso do caso talidomida como exemplificação de contextos de Ensino Superior nos quais o principal assunto abordado pelos professores era substâncias enantioméricas. Descrevemos a seguir, de forma geral, a aula de cada professor e o episódio da aula selecionado e, de modo mais detalhado, o fragmento no qual a explicação sobre o medicamento talidomida ganhou destaque. A Figura 3 mostra cada um dos professores, em um momento do episódio analisado e, em seguida, os três fragmentos são descritos.
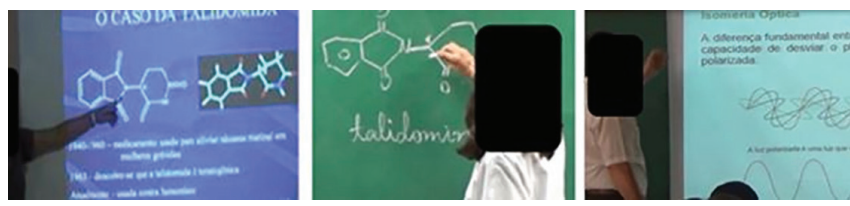

Figura 3. Imagens de tratamento do caso da talidomida por Rosa, Aline e Mateus

\section{Fragmento 1: uso do exemplo da talidomida na aula da professora Rosa}

Na aula de Química Orgânica I, que teve duração de 01 hora, 29 minutos e 35 segundos, a professora Rosa tratou principalmente da quiralidade de moléculas orgânicas e a importância de se conhecê-la quando o estudo se volta para conhecimentos em sistemas biológicos. Ela explorou a nomenclatura de compostos enantiômeros com ligações simples, duplas ou triplas e a atividade óptica desses compostos, além de resolver diversos exercícios sobre esses diferentes temas. A descrição geral dos episódios pode ser vista na Figura 4.

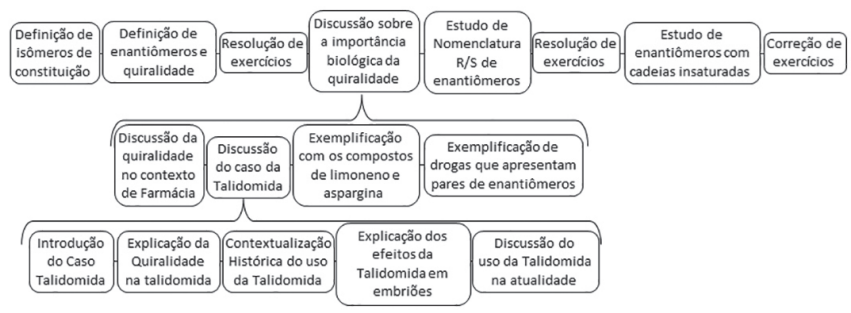

Figura 4. Esquema que representa a aula de Rosa, com os subtemas do episódio no qual emergiu o caso da Talidomida

No quarto episódio (de uma sequência de 8 episódios) da aula, com duração de 06 minutos e 45 segundos, Rosa se dedicou a tratar principalmente da importância biológica da quiralidade. Ela iniciou esse episódio, enfatizando a importância do estudo da quiralidade dentro dos cursos de Farmácia. Segundo suas próprias palavras, "por que é importante / principalmente para vocês que são farmacêuticos estudarem quiralidade / estudarem essas coisas de molécula quiral / lado direito ou esquerdo? Porque se vocês olharem / o nosso corpo humano é totalmente quiral." Com essa fala, Rosa parece ter recebido a atenção dos estudantes, possivelmente por relacionar a disciplina com o campo de atuação. Em seguida, Rosa discutiu o significado da palavra quiral, usando o corpo humano para exemplificar e tratar de algumas substâncias que apresentavam um par de moléculas "imagem-espelho". Com essa analogia, a professora apresentou aos estudantes o que ela chamou de "caso típico da talidomida". Após usar a talidomida como exemplo para tratar de enantiômeros formados quando as moléculas apresentam um centro quiral, a professora apresentou o limoneno e a asparagina, além de citar algumas drogas, tais como anti-inflamatórios e antibióticos, que possuem enantiômeros. Ela ressaltou que o elevado custo de produção de certos medicamentos decorre da necessidade de purificar um enantiômero. Em alguns casos a professora apresentou a representação, projetada em tela, e solicitou que os estudantes identificassem o carbono quiral em suas estruturas.

Foi nesse quinto episódio que a professora Rosa introduziu o caso do uso da talidomida, em um fragmento que durou $02 \mathrm{mi-}$ nutos e 10 segundos. Ela afirmou que a quiralidade da molécula não era muito conhecida quando esse medicamento foi lançado no mercado. Após evidenciar a quiralidade da molécula, ela apresentou uma sequência temporal situando o uso da talidomida como fármaco, principalmente nos Estados Unidos e no Brasil. Com isso, Rosa enfatizou que, ao perceber as consequências para o feto de mulheres grávidas que tomavam a talidomida, imediatamente foi estudada e identificada a interação medicamentosa que ocorria com o enantiômero da substância e seus efeitos no organismo dos embriões. Ela retomou o "encaixe" de um dos enantiômeros com uma enzima, cuja função era reduzir os sintomas de náusea das gestantes, enquanto o outro enantiômero provocava danos ao feto. Nesse momento ela citou:

O outro enantiômero realmente diminuía a náusea. Aí/ o que ((é)) que acontecia? A mulher tomava o enantiômero que encaixava bonitinho lá com o problema da náusea e acabava a náusea / mas em compensação o outro ((enantiômero)) que ficava solto lá no organismo ia para o feto e causava / enforcamento dos membros das crianças. (Professora Rosa)

Ela finalizou esse fragmento apresentando situações de uso da talidomida na atualidade, para controlar algumas doenças, como é o caso da hanseníase. Alertou ainda para o fato do medicamento, mesmo proibido em alguns países, ainda ter sido consumido por gestantes, no Brasil. Após isso ela projetou uma imagem da representação do princípio ativo do medicamento Ibuprofen e solicitou aos estudantes que identificassem o carbono quiral. Imediatamente um deles indicou o carbono, ao que se seguiu o seguinte diálogo:

Professora: o que isso significa?

Estudante: também há dois enatiômeros.

Professora: isso! Um deles age como anti-inflamatório e o outro é inativo.

Com isso, argumentamos que o caso tratado por Rosa - a talidomida - fez com os estudantes percebessem a importância desse estudo e, provavelmente, tenham se apropriado desse conhecimento, a ponto de identificar o carbono quiral em outra representação. 


\section{Fragmento 2: uso do exemplo da talidomida na aula da} professora Aline

Na outra aula de Química Orgânica I, com duração de 01 hora e 19 minutos, Aline fez uma revisão de temas tratados na aula anterior, na qual foi tratada a avaliação de compostos monocíclicos, em especial, em ciclo-hexanos com diferentes conformações (cadeira, bote e torcida). Em seguida, ela apresentou exemplos de moléculas isoméricas que não eram superponíveis umas às outras, mas que possuíam os mesmos grupos ligados a carbonos centrais, de forma a chegar na definição de classes de estereoisômeros utilizando, para isso, modelos moleculares e representações estruturais no quadro de giz. Ato contínuo, ela apresentou algumas substâncias que apresentavam pares de enantiômeros e suas diferentes propriedades. Por último, Aline apresentou os conceitos de quiralidade, ensinando aos estudantes como verificar a presença de carbonos quirais nas estruturas. A fragmentação da aula de Aline em episódios pode ser vista na Figura 5.

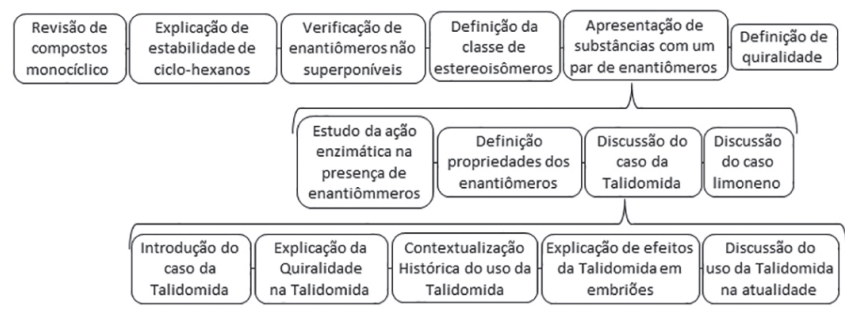

Figura 5. Esquema que representa a aula de Aline, com os subtemas do episódio no qual emergiu o caso da talidomida

O quinto episódio, que teve duração de 12 minutos e 37 segundos, foi iniciado com Aline apresentando a ação enzimática de algumas substâncias que possuem propriedades enantioméricas. Ela afirmou que o fato de apenas um dos enantiômeros fazer o "encaixe" perfeito com uma enzima, mesmo eles sendo aparentemente iguais, era resultado da diferenciação da posição de grupos de átomos que se ligam a um átomo central. Isso, segundo ela, é o que dá origem ao nome "estereoisômeros", por conta da não superposição de uma molécula à outra. A partir disso, ela exemplificou substâncias que apresentavam pares de enantiômeros, enfatizando suas diferentes propriedades e aplicações. Dentro desse episódio, ela discursou sobre a importância de testes biológicos previamente à comercialização de substâncias como os fármacos. Abaixo, enfatizamos a introdução desse discurso.

Se você / por exemplo tem a produção de um fármaco / uma substância que ela vai ser usada como medicamento e / porventura / ela tem essa característica ((de possuir centro quiral)) apresentada pelo 2-etanol isso / gera duas substâncias que guardam essa relação objeto imagem / estereoisômeros. Então / para que seja comercializada ((tal substância)) você tem que testar. O teste com o outro ((composto)) separado e o teste com a mistura ((dos enantiômeros $))$. Se o teste com o que é objeto e o teste com o que é a imagem / objeto e ima$\mathrm{gem} / \mathrm{e}$ o teste com a mistura / se o teste biológico não der problema nenhum / você pode usar a mistura como fármaco. Mas / caso um seja benéfico e o outro não / você não pode usar. (Professora Aline)

Após essa fala, Aline apresentou o exemplo do caso da talidomida e do limoneno e também as propriedades de cada um dos respectivos pares de enantiômeros dessas substâncias.

$\mathrm{O}$ fragmento no qual ela se refere ao uso do caso da talidomida teve duração de 03 minutos e 11 segundos. Nele Aline desenhou a estrutura da substância que representava o fármaco e, enquanto desenhava, relatou um pequeno histórico do uso desse medicamento. Com a estrutura desenhada ela ressaltou o carbono quiral e apontou para a estrutura do 2-etanol, desenhada anteriormente, para mostrar que o carbono dessa estrutura tinha a mesma característica do carbono da estrutura da talidomida. Assim como a professora Rosa, Aline foi mostrando que os problemas ocasionados pelo uso da talidomida, antes da descoberta da existência da estrutura enantiomérica no fármaco, contribuíram para o avanço de estudos sobre os estereoisômeros. Ela retomou a imagem/objeto, já tratada anteriormente, para mostrar os enantiômeros da talidomida. Em seguida, ela desenhou a fórmula estrutural do limoneno na lousa e pediu aos estudantes que identificassem o carbono quiral na representação. Finalizando o episódio, Aline ressaltou a importância do estudo dos estereoisômeros, principalmente para a produção de fármacos. Os estudantes se mostraram interessados no assunto, fazendo inúmeras perguntas do tipo "Como faz para separar esses enantiômeros?", "As propriedades são exatamente as mesmas?", "Eles se diferenciam ao reagir?".

\section{Fragmento 3: uso do exemplo da talidomida na aula do professor Mateus}

$\mathrm{Na}$ aula de Química Inorgânica I, ministrada pelo professor Mateus, com duração de 01 hora, 46 minutos e 31 segundos, o tema central foi Isomeria de complexos. Dentro desse tema o professor abordou os diferentes tipos de isomeria que os complexos inorgânicos podem apresentar. Para isso, ele explorou também o conceito de enantiômeros, enfatizando os diferentes tipos de isomeria: isomeria cis e trans; geométrica; óptica; de ligação; de ionização; e de hidratação. Além disso, Mateus explicou como identificar os possíveis planos de simetria nos complexos e também as possíveis geometrias que eles poderiam assumir. A organização sequencial dos episódios pode ser observada na Figura 6.

No contexto de discussão sobre o tipo de isomeria óptica, que correspondia ao terceiro episódio da aula, Mateus focou a importância do equipamento polarímetro (aparelho usado em laboratórios de indústrias farmacêuticas para determinar o ângulo de rotação ótica de luz polarizada, ao passar essa luz pelo material investigado, fornecendo resultados com grande precisão) para a identificação de substâncias que se enquadravam nessa classificação. Durante 12 minutos o tema geometria óptica foi desenvolvido por ele, abordando: a importância do uso de polarímetros, do seu funcionamento e do comportamento da luz plano polarizada em testes com isômeros ópticos; o quanto essa técnica auxiliou para o avanço da ciência ao estudar a atividade óptica de substâncias; a denominação de enantiômeros; as propriedades físico-químicas de alguns deles.

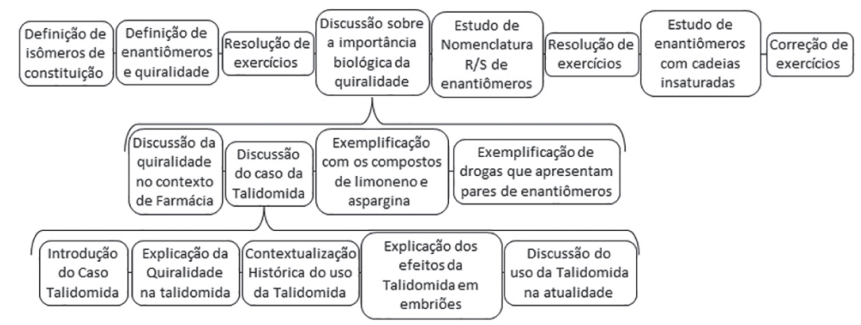

Figura 6. Esquema que representa a aula de Mateus, com os subtemas do episódio no qual emergiu o caso da talidomida

Ao tratar da importância do uso de polarímetro para identificação de compostos que apresentam isomeria óptica, Mateus ressaltou a capacidade desse tipo de isômero em desviar o plano de vibração de uma luz polarizada. Ele fez um breve histórico de estudos que 
contribuíram para a construção desse conhecimento (isomeria óptica), apresentando estudos de alguns cientistas. Em seguida, Mateus retomou exemplos de isômeros geométricos já trabalhados em aulas anteriores, sendo um deles um complexo de platina, no qual o isômero cis é usado como um fármaco enquanto o isômero trans não tem a mesma função. Outro exemplo usado por ele foi o da asparagina, para a qual um dos isômeros confere um sabor doce enquanto o outro confere um sabor amargo.

Nesse contexto de apresentação do polarímetro, Mateus introduziu o caso da talidomida, em um fragmento do episódio 3 que durou 01 minuto e 38 segundos.

Diferentemente das professoras Rosa e Aline, Mateus não apresentou a estrutura química da talidomida nem na lousa nem em imagem projetada. Para citar o exemplo, ele leu parte de um texto que tratava desse medicamento, completando a leitura com falas que pareceram advir de reflexões pessoais.

As informações que emergiram durante a apresentação do caso talidomida giraram principalmente em torno do efeito do desvio da luz plano polarizada quando uma substância contendo o par de enantiômeros era submetida ao teste. Ele, então, explicou os cuidados no uso e na indicação do medicamento na área de saúde, os efeitos do uso do enantiômero na formação de embriões humanos e enfatizou a importância desse conhecimento para a área. Ao se referir à talidomida, ele disse:

Então / um dos isômeros ópticos dela ((da talidomida)) que desviava a luz para a direita / que é o destrógeno / ele era tipo uma / ele tinha uma ação curativa e era usado para náusea /((ou como )) tranquilizante. Por isso (( a talidomida)) era muito indicada para grávidas. Só que as pessoas começaram a tomar / porque não era conhecida ((ainda)) essa propriedade ((isomérica)) com o isômero levo ((levógiro )) que tem propriedades teratogênicas / isto é / má formação dos embriões. (Professor Mateus)

Com isso ele alertou para o fato de que, no tempo em que foi comercializada, sem os devidos testes para possível presença de enantiômeros, a ciência não havia se dado conta dos isômeros ópticos e fez, então, um breve relato do caso desse fármaco. Nesse contexto, ele enfatizou a importância do estudo desses isômeros e a dificuldade que significava separá-los, o que eleva o custo de produção e, por consequência, o custo de para o consumidor final. Ressaltamos que Mateus não abriu espaço para o diálogo e, assim que terminou o relato do caso talidomida, voltou para a lousa e continuou a explicação relativa à quiralidade.

\section{DISCUSSÃO}

Considerando que, segundo pesquisadores da área, ${ }^{14-16}$ a aprendizagem também depende das oportunidades oferecidas aos estudantes para que possam significar dado conhecimento, podemos perceber que Rosa, Aline e Mateus ofereceram aos estudantes a oportunidade de relacionar conceitos considerados complexos com uma situação do contexto. Quando a estereoquímica, os estereoisômeros, a quiralidade ou a isomeria são tratados em sala de aula sem que os estudantes consigam perceber a importância desses conceitos, provavelmente eles não terão significado e, com isso, os estudantes terão dificuldade em se apropriar deles.

Quando esses professores levaram o caso do medicamento talidomida para o contexto de sala de aula e, com ele, mostraram a importância dos estudos envolvendo a quiralidade e os demais conceitos relacionados a ela, a atenção dos estudantes para com o conteúdo parece ter aumentado significativamente. Um exemplo disso foi o número de perguntas feitas à professora Aline, com as quais os estudantes buscavam mais informações e pediam mais explicação sobre o assunto. Eles buscavam entender como a indústria lida com essa informação ao produzir um medicamento.

Vários autores têm ressaltado, em seus trabalhos, a importância de usar, durante as aulas, situações ou eventos que tenham acontecido fora da sala de aula e que estão relacionados aos conceitos explorados pelos professores, ${ }^{17,18}$ enquanto outros enfatizam que essas situações deveriam surgir dos estudantes e não serem levadas pelo professor. ${ }^{19}$ Porém, ao fazerem uma relação direta e explícita com o campo de atuação desses estudantes, é provável que esses três professores os auxiliaram a significar o conteúdo trabalhado, ao usarem o caso da talidomida. Ao se utilizarem de uma experiência passada ${ }^{20}$ os professores contribuíram para o envolvimento dos estudantes com o conteúdo, o que aumenta significativamente a possibilidade de construção de significados.

Nos três fragmentos envolvendo a talidomida está uma relação importante com o campo profissional para a qual esses estudantes buscam a formação. Com isso, argumentamos que a relação com a profissão é também uma relação pedagógica, ${ }^{16}$ no Ensino Superior.

A relação entre os conceitos científicos e um fenômeno do contexto (nesse caso um fenômeno histórico) propiciou maior envolvimento emocional dos estudantes. Nesse sentido, Scott, Mortimer e Ametler ${ }^{16}$ consideram os sentimentos e emoções como centrais nas atitudes que os estudantes desenvolvem em relação à Ciência e que, ao criar relações pedagógicas que auxiliam na construção do conhecimento, os professores estarão encorajando o envolvimento emocional com a própria aula e com o conteúdo científico nela desenvolvido.

Rosa e Aline estabeleceram uma relação com o contexto e, com isso, ressaltaram a importância do conhecimento da quiralidade e da identificação de enantiômeros quando se trata da produção e consumo de fármacos. Mateus deu uma atenção especial a uma tecnologia - uso de um polarímetro e da luz polarizada - para a identificação dos estereoisômeros, o que também representa uma relação com o trabalho de um farmacêutico.

Como limitador do trabalho desses professores, destacamos o fato de que o contexto levado para a sala de aula foi todo explorado pelo professor. Nós já dissemos que grande parte dos professores universitários tem como prática planejar o conteúdo considerando integralmente o tempo de aula que têm disponível. Ao fazer isso, eles limitam as possibilidades de os estudantes serem coprotagonistas. Eles poderiam, por exemplo, ter solicitado aos estudantes, em aula anterior, realizarem a leitura/investigação do caso e, durante a aula em questão, apenas esclarecer dúvidas sobre o caso para, em seguida, mostrar os conceitos envolvidos, desenvolvendo o conteúdo. Pareceunos que o caso poderia ser apresentado, em uma dessas aulas, com mais tempo, para que os estudantes realmente entendessem outras peculiaridades desse acontecimento. Para isso, no entanto, estamos considerando que um professor saiba que os demais usam esse caso, o que pode não ser verídico.

\section{CONSIDERAÇÕES FINAIS}

Tínhamos como objetivo, ao realizar este trabalho, analisar como professores de Química do Ensino Superior se apropriam de um caso histórico para dar significado aos conceitos que desenvolvem em aulas. Observamos três professores de um mesmo curso usarem o caso "talidomida", relacionando-o a conceitos de isômeros, isomeria óptica, quiralidade, enantiômeros, estereoisômeros, destrógeno/ levógiro, além de tratar da análise em aparelho chamado polarímetro.

Ao fazer essa relação, esses professores demonstraram haver uma ligação direta e intensa entre um fato histórico e os conceitos científicos explorados nas aulas. Está claro para nós que, ao perceber 
o potencial interesse e relevância para os estudantes, os professores disponibilizaram uma ligação pedagógica para que seus estudantes pudessem entender a importância do estudo envolvendo enantiômeros para que casos semelhantes não mais se repitam. Com isso, criaram uma relação pedagógica ${ }^{16}$ que provocou o envolvimento emocional dos estudantes, já que perceberam a direta relação do caso tratado com o campo de trabalho futuro.

Porém, o potencial desse fato histórico teria sido melhor explorado se os professores trabalhassem mais sintonizados, fazendo também as relações de continuidade, nas quais fariam referência ao assunto trabalhado pelos colegas. Não temos garantia de que os estudantes perceberam essas relações temporais. Se essas relações estivessem presentes, certamente teríamos um currículo mais integrado.

\section{REFERÊNCIAS}

1. Pimenta, S. G.; Anastasiou, L.; Docência no Ensino Superior, $2^{\mathrm{a}}$ ed, Cortez: São Paulo, 2005.

2. Isaia, S. M.; Em Docência na educação superior, INEP, 2006, p. 63.

3. Ferreira, M. P. M.; Revista Iberoamericana de Educación 2009, 50, 1.

4. Chaves, T. A.; Tese de Doutorado, Universidade Federal de Minas Gerais, Brasil, 2009.

5. Quadros, A. L.; Mortimer, E. F.; Quim. Nova 2016, 39, 634.

6. Quadros, A. L.; Mortimer, E. F.; Ciência \& Educação 2014, 20, 259.

7. Quadros, A. L.; Mortimer, E. F.; Aulas no Ensino Superior: estratégias que envolvem os estudantes, Appris: Curitiba, 2018.

8. Silva, F. A. R.; Tese de Doutorado, Universidade Federal de Minas Gerais, Brasil, 2011.

9. Mortimer, E. F.; Moro, L.; Quadros, A. L.; Coutinho, F. A.; Silva, P. S.; Pereira, R. R.; Santos, V. C.; Revista Brasileira de Pesquisa em Educação em Ciências 2015, 15, 10.

10. Reis, R. P.; Dissertação de Mestrado. Universidade Federal de Minas Gerais, Brasil, 2015.

11. Mortimer, E. F.; Quadros, A. L.; Multimodalidade no Ensino Superior, Ed. Unijuí: Ijuí/RS, 2018.

12. Brito, C. R. N.; Silva, F. C. V.; Simões Neto, J. E.; Ensino de Ciências e Tecnologia em Revista 2018, 8, 14.
13. Locatelli, S. W.; Revista Docência do Ensino Superior 2017, 7, 13.

14. Engle, R. A.; Journal of the Learning Sciences 2006, 15, 451.

15. McDonald, S.; Kelly, G. J.; Pedagogies: An International Journal 2007, 2,165 .

16. Scott, P.; Mortimer, E.; Ametller, J.; Studies in Science Education 2011 , 47,3 .

17. Rivet, A. E.; Krajcik, J. S. J.; Res. Sci. Teach. 2008, 45, 79.

18. Silseth, K.; Instructional Science 2018, 46, 291.

19. Wiig, C.; Silseth, K.; Erstad, O.; Language and Education 2017, 32, 43.

20. Rocksén, M.; Olander, C.; Res. Sci. Educ. 2017, 47, 451.

21. Havekes, H.; van Boxtel, C.; Coppen, P-A.; Luttenberg, J.; Historical Encounters: a journal of historical consciousness, historical cultures, and history education 2017, 4, 71.

22. Quadros, A. L.; Silva, A. S. F.; Mortimer, E. F.; Quim. Nova 2018, 41, 227.

23. Hoffman, R.; O mesmo e o não-mesmo; Ferreira, R. L., trad.; UNESP: São Paulo, 2007.

24. Souza, K. R. A. P.; Dissertação de Mestrado, Universidade Federal Fluminense, Brasil, 2015.

25. Aquino, K. A. S.; Cavalcante, P. S.; Revista Electrónica de Enseñanza de las Ciencias 2017, 16, 117.

26. Sulzbach, A. C.; Dissertação de Mestrado, Universidade Federal de Santa Maria, Brasil, 2017.

27. Gomes, A. O.; Costa, J. S.; Perspectivas da Ciência e Tecnologia 2017, 9,62 .

28. Raupp, D.; Del Pino, J. C.; Acta Scientiae 2015, 17, 146.

29. Silva, M. W. F.; Costa, Y. F.; Marcelino Jr., C. A.; Anais da XIII Jornada de Ensino, Pesquisa e Extensão, Recife, Brasil, 2013.

30. Almeida, R. B.; Mendes, D. H. C.; Dalpizzol, P. A.; Rev. Cienc. Farm. Basica Apl. 2014, 35, 347.

31. Magedanz, A.; Herber, J.; Silva, M. C. A.; Revista Destaques Acadêmicos 2016, 8, 8 .

32. Oliveira, L. A.; Dissertação de Mestrado, Universidade Federal de Minas Gerais, Brasil, 2018.

33. Mortimer, E. F. Massicame, T.; Buty, C.; Tiberghien, A.; Em A pesquisa em ensino de ciência no Brasil: alguns recortes; Nardi, R., ed.; Escrituras: São Paulo, 2007. 